inflammation was clearly infective, and in the treatment regard was paid to the general as well as the local condition. The wounds were most choroughly purified, but, in addition to this, every effort was made to improve the boy's nutrition, and thereby to augment the resistant power of the tissues and fortify them against further activity of the opposing virus.

\section{DIFFERENTIATION IN RHEUMATIC DISEASES. ${ }^{1}$}

BY HUGH LANE, L.R.C.P. \&C.,

HONORARY MEDICAL OFFICER TO TIIE ROYAL UNITED HOSPITAL, DATH; HONORARY PHYSICIAN TO T'HE EASTERN

$$
\text { DISPENSARY, BATH. }
$$

IT may be regarded as a truism to say that, as the empire of medical science gradually widens its bounds, some of its departments which have in the past attracted but too scant a measure of serious notice are now beginning to receive the attention which is their due; and as in every department of human knowledge the synthetic method precedes the analytic, it is only when we pass from the stage of dealing in broad and general definitions and arrive at that of differentiating and classifying that we can truly say that a subject of this kind has begun to be properly grasped. And in the case of chronic rheumatic diseases so called, the time is not so very far distant when the employment of the single term "rheumatism" was held sufficient, not only as a definition, but as an explanation of numerous other diseases, which it is now found cannot be either diagnosed or cured by the device of merely comprising them under one common term and treating them all alike. It has, therefore, to be kept in view, in approaching the special study of rheumatism, that before grappling with it in its numerous and dis. tressing forms, these must be scientifically detailed and classified by the same methods by which all scientitic knowledge is reached-viz, inductive reasoning based upon extensive and minute observations.

Time was when to the old, the poor, and the overwrought, rheunitism seemed to be the natural and expected conclusion to a life of trouble only capable of being mitigated by the warm clothing which charity might supply, or by proximity to a friendly fireside. It was not provided for or guarded against until its presence made itself felt, for it was looked upon as kismet, a thing that could not be avoided; and the idea of preventing its approach, of looking for constitutional symptoms, or, in fact, attempting anything beyond the mere alleviation of its pain when once the victim was in its grip, was a thing unheard of. We see the burden that lies upon us to relieve these victims, to make life more tolerable for them and better worth living-in fine, to demonstrate to them that something is possible for them beyond mere physical existence, encumbered with pains and discomforts, and to teach them the truth and the meaning of that pregnant aphorism of antiquity, "Non est vivere sed valere vita." It will not, I trust, be looked upon as extravagance to say that by the increase of careful unremitting investigation into the various kinds of rheumatic diseases, especially with regard to their early and curable stages and the marks by which they may then be recognised, a better and higher result will inevitably be reached-viz., that in good time such symptoms and such effects will no longer be visible, and we shall no longer have amongst us the crippled frames we so frequently see and the lives of misery which are so often transmitted to an enfeebled posterity. This consummation, so devoutly to be wished, is, I fervently believe, no visionary's dream of the future, but is an actuality almost at hand. It is with such a result in view, and with the hope that the present proceedings may in some small degree contribute to it, that this paper has been written and the subject brought to the front. Its object is to endeavour to throw some further light upon the doubts which exist as to what the differences are between the varieties of rheumatio diseases so-called. By these I mean the diseases to which the terms "chronic rheumation," "rheumatoid arthritis," "rheumatic arthritis," and what is more popularly known as "rheumatic gout," are applied. A few months ago a work

Being the substance of a communication read before the Bristol Hedico-Cinrurgical Association on Nlay 14th, 1890. on this subject appeared by myself, in conjunction with my friend, Mr. Charles T. Griffiths, in which we set forth our opinions, based upon our experiences, and which were almost purely clinical observations. Although it cannot be hoped to better to any considerable extent those advanced in life who are auffering from a rheumatic affection, in spite of our utmost wishes and endeavours to do so, the subject which we think ought to hold a position of greater prominence than it does is that of giving attention to the early interference in the same disease or in one of those related to it, whether it be in a patient a little younger or much younger. For our experience has been that the tendency for the rheumatoidal element to develop in young persons is terribly on the increase. The result of these observations has been to convince us of the following: that the difference between rheumatism and rheumatoid arthritis is of a greater and far more extensive character than the text. books would lead to believe; and so markedly have clinical facts impressed this truth upon us that the occasion is gladly grasped to explain the results of our research. Fortunately for the success of our cause, our paths have led us into regions where rheumatism, rheumatoid arthritis, and rheumatic arthritis are grouped together for special treatment. In the Royal Mineral Water Hospital at Bath can be seen any day these diseases in all their phases, and with all their distinguishing differences, at any age and in every stage.

It must strike as being suggestive that we should have mentioned rheumatoid arthritis and rheumatic arthritis separately ; the reason for so doing will presently be made evident. But, first of all, let us look at rheumatism as com. pared with rheumatoid arthritis. This condition of chronic rheumatism is usually regarded as a most frequent one, but experience has shown that many of these cases of chronic rheumatism so-called, if inquired into more deeply, will prove to be one or other of the supposed allied diseases to be described later. When the sciatic nerve is attacked by rheumatism we call it "sciatica"; when the lumbar muscles, "lumbago"; when certain nerves, we employ the term "neuralgia"; and yet all, in spite of their change of name, claim a share in their relation to chronic rheumatism. We do not mean to offer any objection to this arrangement-it is, in fact, by adopting this quasi-complication we come to simplification; but when the term "chronic rheumatism" is used, it seems to me that it could not be utilised for better and clearer designation than in those cases in which the joints are painful but not swollen, or in which there is a neuralgia or even arthralgia associated with myalgia, or apart from it ; or in which the various fasciæ are affected, or in which there is a general neuralgic condition supervening on an acute attack of rheumatism. This is what we prefer to call "chronic rheumatism." But in speaking of the symptoms of rheumatoid arthritis, I will make reference to those symptoms which are sometinies put down as common to both. Let us imagine two patients sitting side by side, one with chronic rheumatism and the other with rheumatoid arthritis. Now, what do we see? In the rheumatoid arthritis case the first thing that strikes us is most probably the pallor of the patient, as compared with the chronic rheumatic. We look a little closer, and the next thing we perceive will most probably be the joints. The patient with chronic rheumatism will present in this feature little or nothing; whereas, on the other hand, the rheumatoid arthritis patient will be more or less crippled. There will be distinct muscular atrophy in the rheumatoid arthritis case, and the complexion will present the pallor mentioned before, showing on closer inspection yellowish tinges on the face, neck, and perhaps elsewhere. If we agk both patients if they ever had rheumatic fever, they both will probably say No; but further inquiry will elicit the probable fact that the family history of the patient with rheumatism will be a good one, or perhaps at the most a rheumatic one, while the rheumatoid arthritis patient in most cases gives or shows a strumous taint. It is upon the basis of this strumous taint that we feel we must look for further assistance to guide us in the treatment of this terribly crippling malady. It is nearly always present more or less. We are aware that this strumous history has not been particularly referred to in other descriptions of the disease. It being the almost invariable accompaniment has induced us to bring the matter forward. In fact, to look upon struma and rheumatoid arthritis as cause and effect has seemed to us the one plain characteristic in our investigations. Space does not allow of our going far afield for instances in support of the truth of this: the facts we 
have stated have been so palpable and the distinctions at once so clear that perhaps it is wholly unnecessary. We would, however, make one exception and give one circumstance in support of the theory. Take, for instance, the disease known as Charcot's disease: we see the condition which prevails in the joints, and on further inquiry we find a tabetic history. It is not for us to assert that the tabes and joint disease are cause and effect; but when we find a patient with a personal or family history of scrofula, struma, or tabes suffering from an affection of the joints in which no pre-existing attack of rheumatism can be proved, are we very wrong in believing there is such a thing as cause and effect in the case we have before us?

Now, why have we mentioned rheumatoid arthritis and rheumatic arthritis as two distinct diseases? For the following reasons. Rheumatic arthritis is, we consider, an arthritis produced by rheumatism, be the attack acute or subacute. It may be asked now, Then what is chronic rheumatism of $a$ joint when it supervenes on an acute attack? Is it rheumatic arthritis? In the strictest sense of the term it is ; but what concerns us is not so much the difference between chronic rheumatism supervening on an acute attack with little joint affection and chronic rheumatic arthritis supervening on an acute attack with considerable joint implication, so much as the difference between chronic rheumatic arthritis and chronic rheumatoid arthritis.

I assert at once that the main difference is in the cause, and I shall also at once say that the main difference does not hesitatingly call a "mixed case." Again, in rheumatic arthritis the swellings, although positive enough in themselves, can be characterised by many negative sions; for instance, there is not the thickening of the capsule to the same extent as in rheumatoid arthritis, and then there is no effusion; the swellings seem to be due to the intraarticular cartilages and capsules combined. When emaciation occurs, as it so frequently does in these cases, the condition of joint deformity is well seen. Taking, for example, the metacarpo-phalangeal articulations which are so frequently affected, so much disorganisation of joint structure takes place that distinct dislocation of the heads of the phalanges is noticed, causing the heads of the metacarpal bones to stand out, exposing about two-thirds of their articular surfaces; this seems to be the condition when disorganisation of tissue has taken place; but when disease has occurred and an attempt at organisation has gone on, adhesions have formed, and the joints are apparently ankylosed. In these cases the swellings are still less marked, it being quite common to observe no departure from the natural size, and yet, perhaps, the joints are moulded together, producing an actual condition of synostosis. What diagnosis are we to put upon the results of acute rheunatism coming on in a patient already suffering from a previous arthritis which has had its origin in a more or less obscure manner? That must depend upon the ultimate clinical appearances prevailing. An important consideration here presents itself. Assuming that the patient
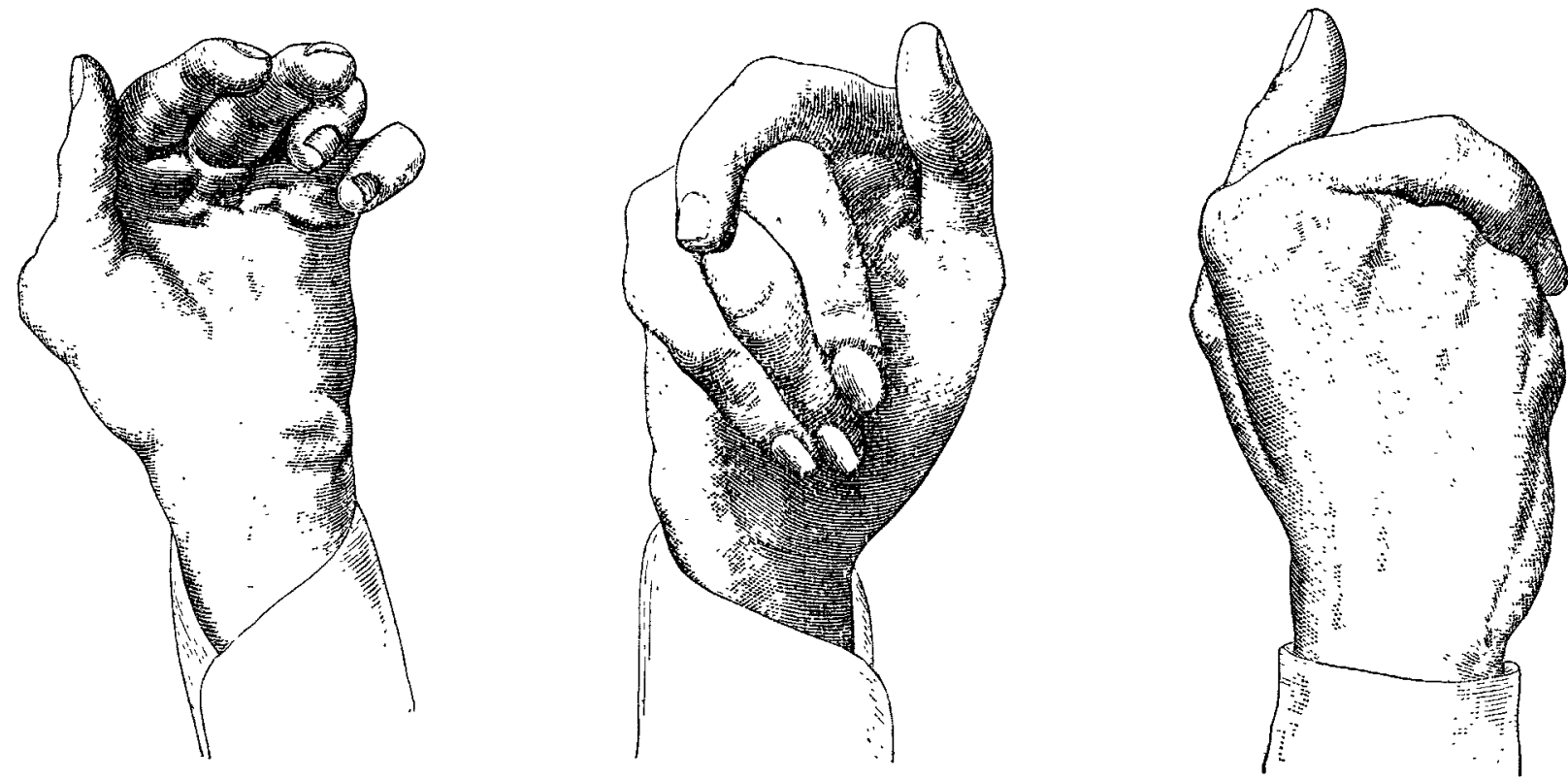

Hands of A. P-. Admitted Jan. 7th, 1889. Fifteen years previously he developed rheumatoid arthritis in several joints of both hands. This went on for two years without much change, and then he had an acute attack of rheumatism, after which the joints gradually assumed the above appearance. The above illustrates a good example of the typical deformities of a "mixed case."

stop short at the cause. In these rheumatic arthritis cases we shall find that the characters-that the physical characters of the joints implicated-present a very considerable difference; there is frequently a flexion and fixation in the phalangeal joints, accompanied by a swelling which ends abruptly above and below each joint, whether in those fixed or not, which is not observable in rheumatoid arthritis, for in rheumatoid arthritis the swellings have strong inclinations to be spindle shaped-that is, graduating into the normal parts. It seems a singular fact that the proximal phalangeal joints of the second fingers are the favourite ones attacked in rheumatoid arthritis, and if a monarthritis, still more so is it the case. In rheumatic arthritis we have found a monarthritis more the exception than the rule. Among the leading characteristic constitutional symptoms of rheumatoid arthritis may be mentioned the following: general weakness, anæmia, emaciation, loss of appetice, arthralgia, lassitude, and the various typical neuroses, which we have described elsewhere. We do not deny that these distinctions are sometimes so ill defined as to forbid us deciding upon an arbitrary classification, especially where we find a case of acute rheumatism occurring in a patient suffering from rheumatoid arthritis, or in which it has previously occurred. Here we often see the leading features of both rheumatic and rheumatoid arthritis displayed in the same individual, and yet so satisfied are we with the proof, that in these cases we hold the patient may be suffering from both diseases distinctly; this we un. in this recent attack of acute rheumatiom develops cardiar mischief, will not the effect on the progress of the resulting disease be regulated in proportion as the cardiac lesion is severe or mild? First of all, the action of a heart more or less rendered arbythmical by endocarditis or myocarditis upon a case of rheumatoid arthritis. The mostimportant thing is, perhaps, the fact that tissues, especially muscular ones, already impoverished by the causes of rheumatoid arthritis, now lose another of their sonrces of nutrition by obstructed blood-supply; possibly there may be pulmonary congestion or regurgitation with mal-aeration. That these complica. tions do in any way produce a separate and distinct pathological condition as a result of combined forces is not evident.

The conclusions which I think must be drawn from clinical practice must be stated at the outset to be that rheumatisn and rheumatic arthritis are about as distinct from rheumatoid arthritis as they can possibly be. It may not be out of place to refer to the term "rheumatic gout," which seems to be the favourite term in some of these conditions. Could any term be more misleading when it is intended to convey the idea of a single affection? It at once suggests a eombination of two separate diseases-rheumatism on the one hand, gout on the other. And yet over and over again we find a patient affected at any period of life in which there has been neither the slightest history of rheumatism nor the slightest history of gout, and there is no hesitation shown in at once determining the case as one of rheumatic gout. It may be excusable for a patient, especially one 
having no connexion with the profession, to use such a term ; but for the reasons just stated, does it not seem to be an extravagent departure from the plain facts of medical nomenclature? It has been our rule to speak of osteoarthritis not as a synonym for rheumatoid arthritis, but as an advanced condition of the latter, when beny implication has been distinct enough to merit the use of the Greek word "osteo." By bony implication we mean eburnation, osteophy tic outgrowths, enlargement, flattening-in short, the later stages after the elastic swelling of the soft tissues has manifested itself. It may be satisfactory for us or anyone to be able to grasp the precise con dition, clinical or pathological, ${ }^{2}$ or both, of the cases which present the appearances we have described, but when it comes to a question of treatment we must confess that the success has been proportionate to that which is obtained in the treatment of struma or phthisis - a fact which may go some way to further the theory advanced by us of the asso. ciation between these diseases and rheumatoid arthritis. In point of fact, the treatment which is adopted for the former we have found to be the most serviceable for the latter. When inflammatory adhesions have formed, the question of passive movement has, we have found, been better answered by somewhat more forcible means than have hitherto been laid down. Cases have passed through our hands which have presented themselves with knees flexed, bringing the legs nearly to a right angle with the thigh, which, under chloroform, have been forcibly extended, treated in the orthodox way, and the patient has been placed in a position in which he or she has been able to exercise his or her locomotive powers, instead of passing day after day and week after week a miserable bedridden cripple. The treatment of rheumatic arthritis must be carried on in proportion as the amount of rheumatism is or has been present. If a mixed case, a mixed treatment would be indicated; in short, that element which prevails must be combated by that particular style of treatment which we have elsewhere shown to be the most beneficial.

The after results in all cases will be decided to no inconsiderable extent by the mode of life which the patient pursues, and unfortunately, in so many of the cases from which we have derived so much valuable and interesting information, satisfactorily as they may have been turned out of hospital at one time, have appeared some months later suffering from an aggravation of the symptoms-often so clear as to show that only over-fatigue and often a forced disregard or a self-imposed disregard of rule has taken place; but at the same time it must be admitted that necessity has compelled them to pursue arocations so unconducive to a more satisfactory end. All will allow that this is not a fatal disease, and all must admit that the facilities for gaining information of pathological importance are difficult; but if clinical material is plentiful and if facilities for treatment are at hand, it must also be admitted that we have at least gained two-thirds of the battle. Perhaps the greatest lesson to be learnt from these troublesone complaints, especially rheumatoid arthritis, is to be suspicious and take it in time, by adopting what we have attempted to show is the most desired means. Early interference will often thwart its progress and its accompanying ravages.

In conclusion, let me sum up what we believe to be the result of the preceding observations. We have to the best of our ability endeavoured to show: first, what is the nature and characteristic 3 of the diseases which we are combating and the marks by which they can be recognised ; secondly, the methods of treatment by which their ravages are to be met and relieved, or neutralised. We have not attempted to dogmatise upon the subject; we have merely brought forvard the fruits of laborious, and we trust we may venture to say to some extent original, investigation. In this paper we have not sought to claim any merit for whatever we may have attempted to contribute to the fuller discussion of the subject, for we cannot forget that all contributions made towards medical science, and every fresh ray of light cast upon it, are, in the phrase of one of our greatest philosophers, but the picking up of pebbles by the shore of the ocean. If we should succeed in warding off or postponing indefinitely the serious results which we all know too well, we should indeed have accomplisbed a humane feat; if not, we can take to ourselves the satisfaction that we have done our best in trying. Bath.

2 The pathology of these diseases was most carefully investigated in an article in the Pathological Society's Transactions for 1886, by my brother, Mr. W. Arbuthnott Lane, M.S., F.R.C.S.

\section{NOTES AND REMARKS ON UPWARDS OF FORTY OPERATIONS FOR CANCER WITH ESCHAROTICS.}

\section{BY OWEN PRITCHARD, M.D.}

IT is not my object to advocate the use of escharotics instead of the knife for the removal of malignant disease. I believe, however, that I am in a position to prove that they may be used with great advantage and with almost absolute safety in some few cases where the knife is not so suitable, and that in a greater number of cases they may be used, if desired, instead of the knife, giving very satisfactory results. Very large tumours, involving, say, the whole of the female breast, may be completely destroyed in a few hours practically without pain from beginning to end, and without any constitutional disturbance whatever. I therefore propose to give as concisely as possible the results of upwards of forty operations of this kind performed by myself during the last two years. Bearing in mind the amount of quackery and dishonest practice that has been carried on in all parts of the country by charlatans and cancer-curers, and sometimes even by qualified practitioners, in the " burning treatment of cancer," I have endeavoured in the following paragraphs to avoid any kind of theories, and to state the facts as simply and as openly as possible, in the hope that they may in no way lend themselves to the unscrupulous, or lead anyone to suppose that I claim for escharotics anything more than their proper place as adjuncts to surgery. It is the fact, of course, that escharotics are used, and have been used from time immemorial in surgery, and the mode of their application described in all the surgical text-books; but while cutting surgery, owing to the discovery and introduction of anesthetics and antiseptics, and probably much greater skill and dexterity on the part of the surgeon and more careful attention to all the details of operations \&c., has been most deservedly making marked progress during recent years, the surgery of escharotics, if I may venture to call it so, has been quite at a standstill, if indeed it has not even retrograded. If escharotics are to remain and hold any place, however humble, in the surgery of the future, there is no need of any further apology for endeavouring to define the appropriate cases for their use, the best escharotics for such cases, and especially the best and most scientific mode of applying them. It is bardly necessary to mention that a large percentage of malignant tumours cannot be removed by escharotics, and must therefore be removed by the knife, and that there is a still much larger per. centage where the tumours, although removable by escharotics, are much more expeditiously treated by the knife in the ordinary way. It is here that considerable experience and a great deal of care are necessary on the part of the surgeon, to determine what is the best advice to give to his patients, and, having given that advice which he considers best, to know how far he must insist upon it, and how far he may consult the wishes of his patient in the matter without at the same time descending into unorthodox or unprofessional practice. Unless my experience differs widely from that of other practitioners, it is not a very uncommon occurrence for patients to decline to undergo a knife operation, and, when that is insisted upon, they leave and "try another doctor." Thus most valuable time is lost whilst the suffering patient is going from doctor to doctor, until, alas! it is too late for any surgical interference whatever. I have not found this difficulty with escharotics, and it is questionable whether a surgeon would be consulting the best interests of his patients by absolutely declining to use escharotics in such instances as the above, even though he may believe that a knife operation would be more suitable, for it will probably be admitted on all hands that the complete and early remove of cancerous tumours is of more importance than any other consideration.

It is not necessary for me to trespass on valuable space by describing the composition and mode of application of such escharotics as the Vienna paste, the chloride of zinc or Fell paste, the arsenical paste of Bougard or the arsenical mucilage of Marsden, \&c.; these are already well described in various text-books and the mode of their application widely known. They are most useful in small tumours, such as epitheliomata of the face, vulva, \&c.; but in spite of all that has been said in their praise by their various champions, they are at the best painful and very tedious applications, 